\title{
The Role of the Schumann Acculturation Model in Generation Z English Acquisition Context
}

\author{
Qianqian Ma \\ ${ }^{1}$ Applied Linguistic and TESOL Program, Department of Arts \& Humanities \\ ${ }^{2}$ Columbia University, Teachers College \\ *Corresponding author. Email:qm2157@tc.columbia.edu
}

\begin{abstract}
The present research explored the validity of the Schumann Acculturation Model (1978) for Generation Z learners during their second language acquisition (SLA), which targets Chinese English as a Second language (ESL) students learning English in Canada [7]. The study also investigated correlations between generation Z learners' culture adaptation and speaking proficiency when learning English in an English-speaking country, and other possible factors that impact learners' SLA. 140 Chinese ESL international students answered the background information questionnaire, social distance questionnaire, psychological distance questionnaire, and IELTS speaking score. The result examines that there was no distinct relationship between ESL learners' culture adaptation and language proficiency.
\end{abstract}

Keywords: Second language acquisition (SLA), acculturation model, generation Z, English as a second language (ESL)

\section{INTRODUCTION}

The growing interest in studying English learning and teaching in an English-speaking nation has increased the demand for research into the factors that influence learners' ability to communicate in English. Cultural and ethnic variety, as a result of globalization, causes additional problems in learners' English acquisition due to psychological and social issues. Many people believe that successful SLA is related to the surrounding environment and the connection with L2 in daily life. Schumann's Acculturation Model was designed to consider different variables in influencing the success of immigrants' language acquisition. However, the acculturation model has been widely criticized for being somehow outdated and unreliable due to the limited empirical support and difficulty measuring the social variables, which Schumann claimed as an important factor in the acculturation model [1]. This study examined the validity of Schumann's acculturation model for Generation Z L2 learners and discuss the factors that can impact second language (SL) learners' cultural adaptation.

\section{LITERATURE REVIEW}

\subsection{Theoretical Background}

The Acculturation Model by Schumann (1986) is one of the most major models by examining the SLA, which model suggests that the extent of learner acculturation to the target-language group can lead to the degree of he acquires the SL. According to Schuman's (1978) acculturation method, acculturation is described as the progressive adjustment of a SL learner's own cultural system to the target language culture, and the degree of acculturation level influences the degree of SLA [1].

Schumann's acculturation method also suggests two variables that could influence learners' language acquisition: social and psychological factors. The social variables refer to the degree of social distance for L2 learners in the target language, in which the social distance is the learners' position to the target language group or to become part of the target language group (Schumann, 1978). Schumann (1978) argued that the social distance would effectively impact learners' SLA by influencing the amount of acculturation [7]. The psychological variable is the way that individuals respond to language learning conditions, which is also known as affective factors (Ushioda, 1993). 
The distance between the social and psychological factors contributes to the success of SL learning. Jia et al. (2014) investigated the relationship between the level of the Chinese ESL immigrant adolescents' acculturation on English learning in Canada and concludes the strong relationship between learners' acculturation level and English literacy skills [4]. Jiang et al. (2009) found SL learners benefit from the acculturation process by examining the impact of acculturation on Forty-nine Chinese graduate students' L2-speaking proficiency and pronunciation other than immigrant learners [5]. Many studies proved that there is a strong relationship between acculturation to society and English-speaking proficiency. Thus, Schumann's Acculturation Model examined both the immigration and international learners' acculturation level to the local culture impact their language learning. The gap between social and psychological elements has a role in SL learning performance. Therefore, Schumann's Acculturation suggests that learners would be more successful in learning a SL if they were more favorably socially and psychologically integrated with the TL culture.

\subsection{Acculturation Model Social Variable}

Schumann (1978) argued that the social variable is an important factor in the Acculturation Model to influence language acquisition, in which social distance has been identified into eight degrees [7].

Palfreyman (2006) demonstrated the social distance impact on L2 students' language learning and proved that social dominance, integration pattern, enclosure, and culture congruence are important factors for the language learning process [6]. The participants were 131 female students from the university in the united Arab Emirate in Dubai, they were asked to fill in an anonymous online survey to evaluate the English levels for themselves, most contact family members or/and friends, and other resources to improve their English skills. Palfreyman (2006) analyzed that $70 \%$ of responders acculturated into the target-language group holding a similar lifestyle and value of English-speaking group by using English at home for personal purposes. Participation acculturation and the need to communicate with members of the target language community allow learners to practice English outside school from different social resources, which suggests that social factors play an important role in shaping L2 in learning English, producing and perceiving the L2 like native speakers.

The study from Gatbonton et al. (2005) also found the social distance on second language pronunciation accuracy by contracting two studies between Chinese and French speakers learning English in Canada under different social contexts [2]. The participants were required to fill in the questionnaire based on participants' own standards and responses on the ethnic group affiliation questionnaire and behavioral scales. The study found that Chinese learners do not feel a threat from speaking English and are more motivated to improve the English pronunciation accuracy and reduce the accent than the French learners due to Chinese leaders being socially equal with the English language group, while French learners with more intense nationalism and a higher level of the threat to ethnic group identity [2].

Overall, the study from Palfreyman (2006) and Gatboton (2004) suggests that social distance plays an important role in learning a second language. Different learning contexts, social factors, and group identity influence the learners' motivation and behavior consequences in studying the language. Thus, social distance plays an important role in learning an SL. Different learning contexts, social factors, and group identity influence the learners' motivation and behavior consequences in studying the language.

\subsection{Acculturation Model Psychological Factors}

The acculturation model also suggests the learners' different psychological levels impact learners' language acquisitions.

Graham and Brown (1996) examined the impact of the affective variables to develop native-like proficiency [3]. The participants were required to do the selfassessment of their English ability, demonstrate the acculturation variables and assess their oral proficiency in English based on two interviews, one in Spanish, the other in English. In the first interview, the participants need to do the self-assessment of their English ability in reading, writing, listening, and speaking, as well as demonstrating the acculturation variables in seven social variables and four affective variables. During the second interview, the participants' oral proficiency was evaluated the speaking and speaking abilities. The result concluded that learners who acquire much of the SL are those who hold a favorable attitude toward the Englishspeaking community and develop a close friendship with native English-speaking peers. Thus, affective variables motivate learners in improving English proficiency.

Palfreyman (2006) suggests that participants hold a positive attitude in learning English, which proves the effectiveness of the psychological variables in learning language literacy proficiency [6]. Gatbonton (2005) also demonstrates the positive or negative attitudes for L2 learners impacts learners' pronunciation accuracy [2]. French learners hold negative attitudes toward English, so they are less motivated to improve pronunciation accuracy compared to Chinese learners who hold a positive attitude.

While the evidence of the effectiveness of acculturation is strong, the previous studies fail to control other variables in the research design. The acculturation level is also related to academic achievement, motivation, and contact with the dominant group, and selfconfidence. Thus, the causal relationship between the 
learners' acculturation level and language proficiency is too arbitrary, the result might be unreliable and lacking in generalizability. The number of participants is relatively small.

This study aims to focus on Generation Z ChineseEnglish international students and investigate whether the culture adaptation impacts their language proficiency based on Schumann's Acculturation Model. The research considered other variables, including motivation, teaching quality, self-confidence, English environment, and after-school learning. The study aims to bridge the gap between the literature on the validity of Schumann's Acculturation Model in generation $\mathrm{Z}$ international students learning English in an English-speaking country. Here are the research questions for the study:

(1)Is there a relationship between the ESL learner's acculturation level and English literacy skills?

(2)Whether the Acculturation Model is still a valid theory?

(3)What teacher can learn from the Acculturation Model and apply it to the class setting?

\section{METHOD}

This study collected the data based on the convincing sampling method, and all the quantitative data was collected through questionnaires. All participants were required to fill in a battery of questionnaires. The battery of questionnaires consisted of the background information questionnaire, social distance questionnaire, psychological distance questionnaire, and IELTS speaking score. The social distance and psychological distance questionnaires were designed based on Schumann's Acculturation Model.

Approximately 140 participants were required to first answer the background information, which includes their basic demographic information, and ensured the participants were in generation $\mathrm{Z}$.

The language competency was collected based on the self-evaluated method to collect the quantitative data. The research first carried out the pilot study to decide which language proficiency be evaluated by asking 30 participants individually to self-evaluate which language proficiency in terms of listening, speaking, reading, and writing have improved the most, and which aspect has changed less after coming to Canada. Reading proficiency has been reported to change least (52.53\%) and speaking proficiency reported changed the most $(50.00 \%)$. After determining to speak and reading proficiency were the most critical competence, the speaking and reading competencies of the participants were decided by their self-rated speaking and reading improvement after studying or living in Canada scored from 0 to 100 .
The response's degree of acculturation was assessed on a 5-point Likert scale ranging from 1 (strongly disagree) to 5 (strongly agree). The research questions were designed based on a series of questions, including eight social distance questions and 18 psychological distance questions. The participants were required to self-evaluate on the social distance questionnaire and psychological distance questionnaire and choose the answer that can most represent themselves. The average score between the social distance and psychological distance questionnaires represented the level of acculturation level of the participants. Higher the score represented the more acculturation level of the participants, whereas lower the score indicated the less acculturation level. To guarantee comprehension, all questions will be translated into Chinese. And the questionnaires were anonymous. Besides the speaking competence, reading competence, and acculturation level, the questionnaires also reported the participants' length of residence, and the level of teaching quality, selfconfidence, language environment, and motivation.

The descriptive statistics for students' degree of cultural adaptation will be analyzed using Excel, which will include the percentage, mean, standard deviation mode, median, and range. The referential analysis (ANOVA analysis) was conducted to explore the correlation between participants' culture adaptation with listening proficiency, reading proficiency, and other factors.

\section{CONCLUSION}

The questionnaire investigated 140 Chinese ESL international students, who have studied or lived in Nova Scotia, Canada. All of the participants have taken IELTS tests within 6 months after coming to Nova Scotia. More than $90 \%$ of participants in L1 were Mandarin, other languages including Cantonese (5\%) and Hakka (2.86\%). Participants were born from 1997 to 2012, and the genders were almost evenly distributed (male $47.14 \%$, female $52.86 \%$ ). Participants came to NS for language school, university, high school, and international programs. The length of residence for the participants was from half of the year to seven years. Pupils should have established a fundamental English knowledge framework, $66.43 \%$ of the participants reported they have learned more than five years of English and were able to speak at least a little English. Almost half of the participants rated their frequency of using English in Nova Scotia as similar to using Chinese.

The result found out that there is no distinct relationship has found between the participants' speaking proficiency and reading proficiency with culture adaptation $(r=.37706058$ and $r=.16115524$ respectively), and other factors (motivation: $\mathrm{r}=.556469505$, teaching quality: $\mathrm{r}=.3956124$, self- 
confident: $\quad r=.54636541$, English environment: $r=.47679153$, after-school learning: $r=$.47535596).

The Schumann Acculturation Model might no longer be valid for Generation Z SL learners that are learning English in an English-speaking country. Furthermore, the small sample size also reduced the external validity. The future study will explore the relationship between learners' culture adaptation and speaking proficiency change over a period of time. However, it is still helpful if the language teacher understands the learners'

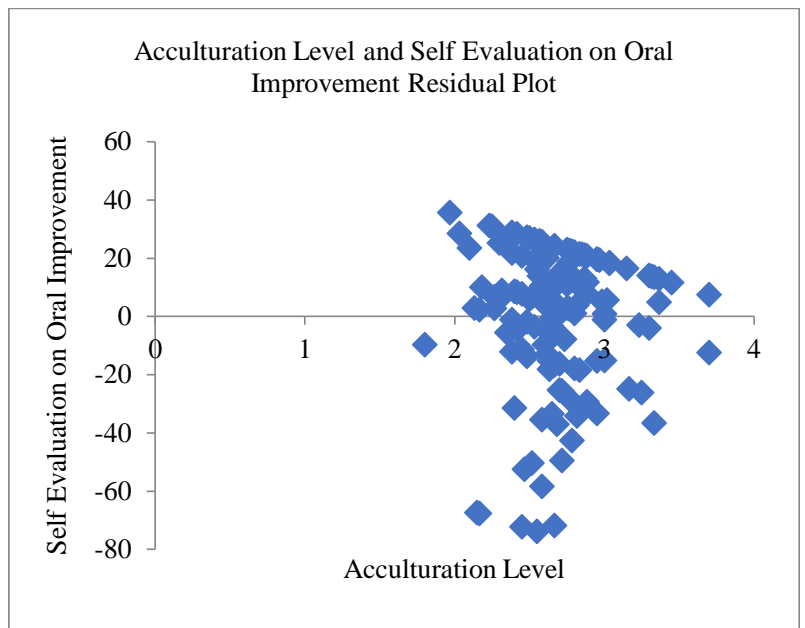

Figure 1. Residual Plot between Acculturation level and self-rated oral improvement

\section{REFERENCES}

[1] Ellis, R. (2015). Understanding Second Language Acquisition. Oxford: Oxford University Press.

[2] Gatbonton, E., Trofimovich, P., \& Magid, M. (2005). Learners' ethnic group affiliation and L2 pronunciation accuracy: A sociolinguistic investigation. TESOL Quarterly, 39, 489-511.

[3] Graham, C., \& Brown, C. (1996). The effects of acculturation on second language proficiency in a community with a two-way bilingual program. The Bilingual Research Journal. Vol. 20, No. 2, pp. 235260.

[4] Jia, F., Gottardo, A., Koh, P., Chen, X., \& Pasquarella, A. (2014). The Role of Acculturation in Reading a Second Language: Its Relation to English Literacy Skills in Immigrant Chinese Adolescents. Reading Research Quarterly, 49(2), 251-261.

[5] Jiang, M., Green, R, Henley, T., \& Masten, W. (2009). Acculturation in relation to the acquisition of a second language, Journal of Multilingual and Multicultural Development, 30:6, 481-492,

[6] Palfreyman, D. (2006). Social context and resources for language learning. System, 34, 352-370. acculturation level and cultural background to improve their English literacy in a more efficient way. Also notice that the immersion is a gradual and slow process and might have a differing impact on learners when they hold different social backgrounds, including ethnic heritage, lifestyle, value, length of residence. Teachers could adapt the acculturation model along with other teaching models to achieve the effectiveness of the learners' language acquisition in both the short-term and long-term

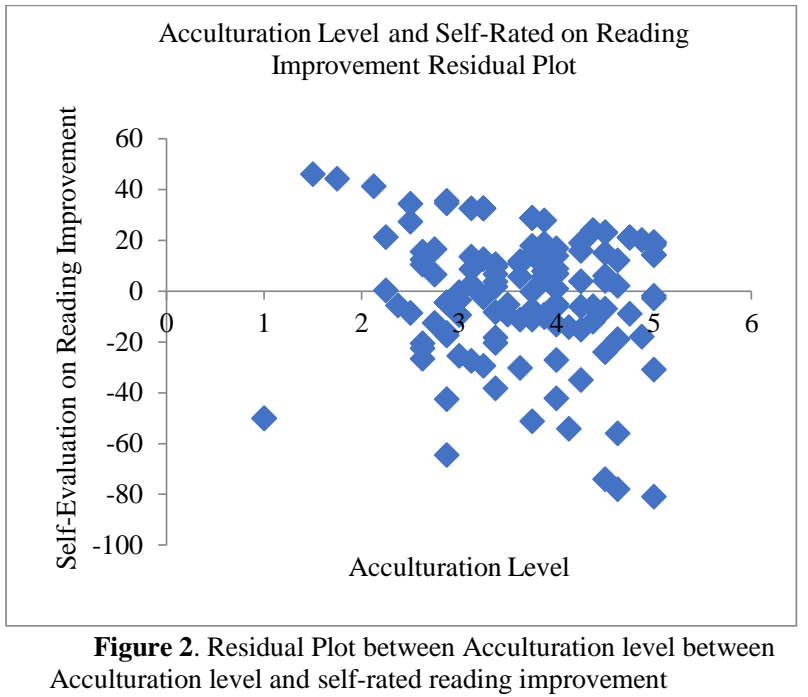

[7] Schumann, J. H. (1986). Research on the acculturation model for second language acquisition. Journal of Multilingual \& Multicultural Development, 7(5), 379-392. 